\title{
Combination of deep sea water and Sesamum indicum leaf extract prevents high-fat diet-induced obesity through AMPK activation in visceral adipose tissue
}

\author{
HAIDAN YUAN ${ }^{1,2^{*}}$, SUNGHYUN CHUNG ${ }^{3 *}$, QIANQIAN MA ${ }^{1}$, LI YE ${ }^{1}$ and GUANGCHUN PIAO ${ }^{1,2}$ \\ ${ }^{1}$ Department of Pharmacognosy, College of Pharmacy, Yanbian University; ${ }^{2}$ Key Laboratory of Natural Resources of Changbai \\ Mountain and Functional Molecules, Ministry of Education, Yanbian University, Yanji, Jilin 133000, P.R. China; \\ ${ }^{3}$ Department of Pharmacology, College of Pharmacy, Kyung Hee University, Seoul 130701, Republic of Korea
}

Received October 9, 2014; Accepted September 1, 2015

DOI: $10.3892 /$ etm.2015.2852

\begin{abstract}
The aim of the present study was to evaluate the protective effects of a combination of deep sea water (DSW) and Sesamum indicum leaf extract (SIE) against high-fat diet (HFD)-induced obesity and investigate its molecular mechanisms in adipose tissue. ICR mice were randomly divided into three groups: HFD control (HFC), DSW and DSW $+125 \mathrm{mg} / \mathrm{kg}$ SIE (DSS) groups. The mice in the HFC group had free access to drinking water while those in the DSW and DSS groups had free access to DSW. The mice in the DSS group were treated with SIE once per day for 8 weeks. The mice in all three groups were allowed to freely access a HFD. Compared with the HFC group, the DSS group showed lower body weight gain and serum levels of glucose, triglycerides and leptin. Histological analyses of the epididymal white, retroperitoneal white and scapular brown adipose tissue of mice in the DSS group revealed that the adipocytes were markedly decreased in size compared with those in the HFC group. Moreover, DSS significantly increased the levels of phosphorylated adenosine monophosphate-activated protein kinase (AMPK) and its substrate, acetyl-CoA carboxylase (ACC) in mice epididymal adipose tissues. Furthermore, DSS upregulated the expression levels of lipolysis-associated mRNA, specifically peroxisome proliferator-activated receptor- $\alpha$ (PPAR- $\alpha$ ) and cluster of differentiation 36 (CD36), and energy expenditure-associated mRNA, namely uncoupling protein 2 (UCP2) and carnitine palmitoyltransferase-1 (CPT1) in the
\end{abstract}

Correspondence to: Dr Guangchun Piao, Department of Pharmacognosy, College of Pharmacy, Yanbian University, 977 Gongyuan Lu Street, Yanji, Jilin 133000, P.R. China

E-mail: gcpiao@ybu.edu.cn

*Contributed equally

Key words: obesity, high-fat diet, deep sea water, Sesamum indicum leaf epididymal adipose tissues. By contrast, DSS suppressed the expression of the lipogenesis-related gene sterol regulatory element-binding protein-1 (SREBP1) at the mRNA level. These results suggest that DSS is effective for suppressing body weight gain and enhancing the lipid profile.

\section{Introduction}

Obesity is a metabolic syndrome caused by an imbalance between energy intake and expenditure. It is associated with a number of health problems, including hyperlipidemia, hypertension, type 2 diabetes, coronary heart disease, cancer, respiratory complications and osteoarthritis $(1,2)$. The degree of obesity is dependent on the amount of body fat and it has been indicated that obesity is associated with various factors $(3,4)$. A high-fat diet (HFD) is one of the most important environmental factors associated with obesity. Chronic exposure to a HFD can affect the generation of and reaction to meal-related signals that control food intake and metabolism (5). When a diet with a high-fat content is consumed on a regular basis, some of the fat remains in the body and results in the accumulation of excessive body fat (6). Visceral fat, which is formed around the major organs, stores energy in the form of triglycerides (TGs) and its accumulation has a pathophysiological role in the development of metabolic syndromes including obesity, hyperlipidemia and diabetes $(7,8)$.

Anti-obesity drugs such as orlistat, sibutramine and topiramate are currently used to treat obesity (9). However, these drugs have numerous side-effects, including dry mouth, anorexia, insomnia and gastrointestinal indisposition (10). Due to the adverse side-effects of certain anti-obesity drugs, functional foods made from natural plants are also being used to prevent and ameliorate obesity (6). Deep sea water (DSW) generally refers to sea water from a depth of $>200 \mathrm{~m}$ (11). DSW has been the subject of many studies due to its high content of inorganic nutrients such as magnesium $(\mathrm{Mg})$, calcium $(\mathrm{Ca})$, potassium $(\mathrm{K})$, zinc $(\mathrm{Zn})$ and vanadium $(\mathrm{V})$, and has been indicated to be associated with prevention of obesity (11-15). Sesame (Sesamum indicum L.), which is an annual herbaceous plant, has long been an ingredient 
in human foods (16). The leaves, seed and oil from sesame plant are consumed locally as food products in China, South Korea, Japan and many other countries (17). However, to the best of our knowledge the biological functions of a combination of DSW and Sesamum indicum leaf extract (SIE) in weight-reduction and its regulatory effects on obesity-related metabolic diseases have not been documented.

In the present study, the protective effects of a combination of DSW and SIE were evaluated against HFD-induced obesity and the underlying molecular mechanisms of the effect were elucidated in the epididymal adipose tissues of ICR mice.

\section{Materials and methods}

Materials. DSW was obtained from Herb Valley Life Science (Seoul, Korea); rabbit anti-mouse polyclonal phospho-adenosine monophosphate-activated protein kinase (p-AMPK $\alpha$; cat. no., 2531L; dilution 1:2,000), rabbit antimouse polyclonal AMPK $\alpha$ (cat. no., 2532S; dilution 1:2,000), rabbit anti-mouse polyclonal phospho-acetyl-CoA carboxylase (p-ACC; cat. no., 3661L; dilution 1:2,000) and rabbit anti-mouse polyclonal ACC (cat. no., 3662; dilution 1:2,000) antibodies were from Cell Signaling Technology (Beverly, MA, USA); goat anti-mouse polyclonal immunoglobulin G (IgG) actin antibody (cat. no. sc-1616; dilution, 1:1,000) was from Santa Cruz Biotechnology (Dallas, TX, USA); and the HFD was purchased from Research Diets Inc. (D12451; New Brunswick, NJ, USA).

Preparation of SIE. Sesamum indicum leaves were purchased from commercial sources and were dried in the shade for 1 week. An extract was prepared by boiling the leaves in $70 \%$ ethanol for $5 \mathrm{~h}$. Following filtration and evaporation, the solution was evaporated under vacuum to provide a powdered extract.

Animals. Four-week-old ICR seco were purchased from Orient Bio Inc. (Seoul, Korea). The animals were housed for 1 week and fed a standard diet under environmentally controlled conditions. The mice were allowed to freely access drinking water and food under constant room temperature $\left(22 \pm 2^{\circ} \mathrm{C}\right)$ and humidity $(50 \pm 10 \%)$ conditions with an automatic 12 -h light and 12-h dark cycle, and were cared for and treated in accordance with the guidelines for the Care and Use of Laboratory Animals (1996) (18). A tor mice were randomly divided into three groups (6 mice per group): HFD control (HFC), DSW and DSW + $125 \mathrm{mg} / \mathrm{kg}$ SIE (DSS). Mice in the HFC group had free access to drinking water and the mice in the DSW and DSS groups had free access to DSW instead. The mice in the DSS group were treated with SIE by oral administration once per day for 8 weeks starting 3 days prior to the provision of the HFD. The mice in all groups were allowed to freely access the HFD. The composition of the experimental diet is shown in Table I; it is a HFD in which $45 \%$ of the calories are provided by fat. The body weight gain was measured once every week.

Determination of serum parameters. After 8 weeks of treatment, animals were fasted for $12 \mathrm{~h}$ and then blood samples were collected and centrifuged at $3,000 \mathrm{xg}$ for $15 \mathrm{~min}$ at $4^{\circ} \mathrm{C}$.
Table I. Composition of the experimental diet.

A, Nutritional profile

\begin{tabular}{lcc}
\hline Component & $\mathrm{g} \%$ & $\mathrm{kcal} \%$ \\
\hline Protein & 24 & 20 \\
Carbohydrate & 41 & 35 \\
Fat & 24 & 45 \\
\hline
\end{tabular}

B, Composition

\begin{tabular}{lcc}
\hline Ingredient & $\mathrm{g}$ & $\mathrm{kcal}$ \\
\hline Casein (from milk) & 200 & 800 \\
Corn starch & 155.0 & 620 \\
Sucrose & 50 & 200 \\
Dextrose & 132 & 528 \\
Cellulose & 50 & 0 \\
Soybean oil & 25 & 225 \\
Corn oil & 175 & 1,575 \\
Mineral mixture & 35 & 0 \\
Vitamin mixture & 10 & 40 \\
TBHQ & 0.014 & 0 \\
L-Cystine & 3 & 12 \\
Choline bitartrate & 2.5 & 0 \\
Total & 837.6 & 4,000
\end{tabular}

The diet provides $4,776 \mathrm{kcal} / \mathrm{kg}$. TBHQ, tert-butylhydroquinone.

The levels of serum glucose, insulin, TGs and leptin in the serum were measured. Serum glucose concentrations were determined using a commercial kit based on the glucose oxidase method (Asan Pharmaceutical Co., Seoul, Korea). Serum insulin concentrations were determined using a mouse insulin enzyme immunoassay kit (Shibayagi, Gunma, Japan). Serum TG concentrations were determined using a commercially available kit (Asan Pharmaceutical Co.). Leptin levels were measured using a mouse leptin enzyme immunoassay kit (Linco Research, Inc., St. Charles, MO, USA). Homeostasis model assessment of insulin resistance (HOMA-IR) values were calculated using the following formula: Insulin $(\mathrm{U} / \mathrm{ml})$ x glucose $(\mathrm{mM}) / 22.5$.

Histological analysis. Epididymal white, retroperitoneal white and scapular brown adipose tissues were removed and fixed in $10 \%$ neutral buffered formalin. The tissues were subsequently embedded in paraffin and sectioned with $5-\mu \mathrm{m}$ thickness (Leica RM2245; Leica Microsystems GmbH, Wetzlar, Germany), and then stained with hematoxylin and eosin (H\&E) for microscopic assessment (Olympus BX51; Olympus Corporation, Tokyo, Japan). The mean adipocyte cell number percentage of epididymal white and retroperitoneal white adipose tissues were measured from the images obtained from H\&E staining using Image-Pro ${ }^{\circledR}$ Plus version 7.0 software (Media Cybernetics, Inc., Bethesda, MD, USA). 
Table II. Effects of deep sea water and Sesamum indicum leaf extract on mouse body weight, food intake and water intake.

\begin{tabular}{|c|c|c|c|c|c|}
\hline \multirow[b]{2}{*}{ Group } & \multicolumn{2}{|c|}{ Body weight (g) } & \multirow[b]{2}{*}{ Weight gain (g) } & \multirow[b]{2}{*}{ Food intake (g/mouse) } & \multirow[b]{2}{*}{ Water intake (ml/mouse) } \\
\hline & Initial & Final & & & \\
\hline $\mathrm{HFC}$ & $26.4 \pm 0.4$ & $38.0 \pm 0.4$ & $11.7 \pm 0.7$ & 144.4 & 257.7 \\
\hline DSW & $25.8 \pm 0.3$ & $36.5 \pm 0.8$ & $10.7 \pm 0.8$ & 138.0 & 305.7 \\
\hline DSS & $26.2 \pm 0.4$ & $34.8 \pm 1.0^{\mathrm{a}}$ & $8.6 \pm 0.9^{a}$ & 129.5 & 302.0 \\
\hline
\end{tabular}

Values represent the mean \pm standard error of the mean $(\mathrm{n}=6) .{ }^{\mathrm{a}} \mathrm{P}<0.05$ vs. the HFC group. HFC, high-fat diet control; DSW, deep sea water; DSS, DSW + $125 \mathrm{mg} / \mathrm{kg}$ Sesamum indicum leaf extract.

Western blot analysis. At the end of the treatment, the mice were fasted for $12 \mathrm{~h}$, anaesthetized with diethyl ether and blood samples were collected by cardiac puncture. Following blood collection, the mice were sacrificed with diethyl ether. Immediately after sacrifice, epididymal white adipose tissues were removed and instantly soaked in liquid nitrogen for storage at $-70^{\circ} \mathrm{C}$. Protein extracts were prepared using a protein extraction kit (Intron Biotechnology Inc., Seoul, Korea). Lysates (50 $\mu \mathrm{g})$ were electroblotted onto a nitrocellulose membrane following separation by $8 \%$ SDS polyacrylamide gel electrophoresis. Blotted membranes were incubated for $1 \mathrm{~h}$ with blocking solution (Tris-buffered saline/Tween 20, TBST) containing 5\% skimmed milk (w/v) at room temperature, followed by incubation overnight at $4{ }^{\circ} \mathrm{C}$ with a 1:2,000 dilution of primary antibody against AMPK, p-AMPK, ACC or p-ACC. Membranes were washed four times with $0.1 \%$ TBST and incubated with a 1:3,000 dilution of horseradish peroxidase-conjugated goat anti-rabbit or donkey anti-rabbit IgG secondary antibody (cat. no., sc-2313) for $1 \mathrm{~h}$ at room temperature. Membranes were washed four times in TBST and then developed by electrochemiluminescence (Amersham, GE Healthcare, Uppsala, Sweden). Image J 1.49 software (http://rsb.info.nih.gov/ij/download. html; National Institute of Health) was used for the quantification of the results of western blotting.

Reverse transcription-polymerase chain reaction (RT-PCR). Total mRNA was isolated from the epididymal adipose tissue of mice from each group using an Easy-Blue kit (Intron Biotechnology Inc.) according to the manufacturer's instructions. From each sample, total RNA $(10 \mu \mathrm{g})$ was reverse transcribed into cDNA using the Moloney murine leukemia virus transcriptase and Oligo(dT) $)_{15}$ primers (Promega Corporation, Madison, WI, USA). The cDNA fragment was amplified by PCR using the following specific primers: Cluster of differentiation 36 (CD36) sense, 5'-TCC TCTGACATTTGCAGGTCTATC-3' and anti-sense, 5'-GTG AATCCAGTTATGGGTTCCAC-3'; proliferator-activated receptor- $\alpha$ (PPAR- $\alpha$ ), sense 5'-CCCTGAACATCGAGTGTC GA-3' and anti-sense 5'-CTTGCCCAGAGATTTGAGGTC CT-3'; uncoupling protein 2 (UCP2), sense 5'-GCAAGCTCA ATGTTGGTGTCTT-3' and anti-sense 5'-ACTCTGCAGATA GACAGGCCTG-3'; carnitine palmitoyltransferase-1 (CPT1), sense 5'-CCTGGGCATGATTGCAAAG-3' and anti-sense 5'-ACAGACTCCAGGTACCTGCTCA-3'; sterol regulatory element binding protein-1 (SREBP1), sense 5'-GCGCTACCG GTCTTCTATCA-3' and anti-sense, 5'-TGCTGCCAAAAG ACAAGGG-3'; and cyclophilin (CPN), sense 5'-ATGGTC AACCCCACCGTG-3' and anti-sense 5'-TTAGAGTTGTCC ACAGTCGGAGA-3'. For PPAR- $\alpha$, UCP2 and CPT-1, PCR was initiated with a thermal cycle of $95^{\circ} \mathrm{C}$ for $5 \mathrm{~min}, 95^{\circ} \mathrm{C}$ for $30 \mathrm{sec}, 55^{\circ} \mathrm{C}$ for $30 \mathrm{sec}, 72^{\circ} \mathrm{C}$ for $30 \mathrm{sec}$, with amplification for 30 cycles, whereas for CD36, PCR was initiated with a thermal cycle of $95^{\circ} \mathrm{C}$ for $5 \mathrm{~min}, 95^{\circ} \mathrm{C}$ for $30 \mathrm{sec}, 51^{\circ} \mathrm{C}$ for $30 \mathrm{sec}, 72^{\circ} \mathrm{C}$ for $30 \mathrm{sec}$, with amplification for 30 cycles. For SREBP1 and CPN, PCR was initiated with a thermal cycle of $95^{\circ} \mathrm{C}$ for $5 \mathrm{~min}, 95^{\circ} \mathrm{C}$ for $30 \mathrm{sec}, 58^{\circ} \mathrm{C}$ for $30 \mathrm{sec}, 72^{\circ} \mathrm{C}$ for 30 sec, with amplification for 30 cycles. The RT-PCR products were electrophoresed on $1 \%$ agarose gels and visualized by $0.5 \mu \mathrm{g} / \mathrm{ml}$ ethidium bromide staining. Scanning densitometry was performed with the i-MAX Gel Image analysis system (Core Bio System, Seoul, Korea). CPN was amplified as a control gene.

Statistical analysis. All data are expressed as the mean \pm standard error of the mean and differences between the groups were analyzed using a Student's t-test. Mean values were considered significantly different when $\mathrm{P}<0.05$.

\section{Results}

Effects on body weight gain. Table II shows the effects of DSW and SIE on body weight gain in the mice with HFD-induced obesity following treatment for 8 weeks. The final body weights were reduced by $3.95 \%$ in the DSW group and $8.42 . \%(\mathrm{P}<0.05)$ in the DSS group compared with those in the HFC group. These results indicate that the DSS combination may have an inhibitory effect against HFD-induced body weight gain. The HFC group showed the highest food intake and lowest water intake among the groups, whereas the DSS group showed a reduction in food intake and increase in water intake (Table II).

Effects on serum parameters. Table III shows the effects of DSW and DSS on metabolic parameters in the mice with HFD-induced obesity following treatment for 8 weeks. plasma glucose levels were significantly decreased by $14.9 \%$ in the DSW group and $36.4 \%(\mathrm{P}<0.01)$ in the DSS group compared with those in the HFC group. However, no significant differences were observed in plasma insulin 
Table III. Effects of deep sea water and Sesamum indicum leaf extract on fasting plasma glucose and insulin levels, and homeostasis model assessment values for insulin resistance.

\begin{tabular}{lccr}
\hline Group & Blood glucose $(\mathrm{mM})$ & Insulin $(\mathrm{U} / \mathrm{ml})$ & HOMA-IR \\
\hline HFC & $15.4 \pm 0.7$ & $200.4 \pm 9.9$ & $137.3 \pm 10.5$ \\
DSW & $13.1 \pm 1.4$ & $179.2 \pm 14.9$ & $106.4 \pm 15.6$ \\
DSS & $9.8 \pm 1.0^{\mathrm{a}, \mathrm{b}}$ & $177.1 \pm 11.5$ & $84.9 \pm 11.1^{\mathrm{c}}$ \\
\hline
\end{tabular}

Values represent the mean \pm standard error of the mean $(n=6)$. Homeostasis model assessment of insulin resistance (HOMA-IR) was calculated as follows: Insulin $(\mathrm{U} / \mathrm{ml}) \mathrm{x}$ glucose $(\mathrm{mM}) / 22.5$. ${ }^{\mathrm{a}} \mathrm{P}<0.01$ vs. the $\mathrm{HFC}$ group; ${ }^{\mathrm{b}} \mathrm{P}<0.05$ vs. the DSW group; ${ }^{\mathrm{c}} \mathrm{P}<0.05$, vs. the $\mathrm{HFC}$ group. HFC, high-fat diet control; DSW, deep sea water; DSS, DSW + $125 \mathrm{mg} / \mathrm{kg}$ Sesamum indicum leaf extract.

A Epididymal
white adipose

Scapular brown adipose

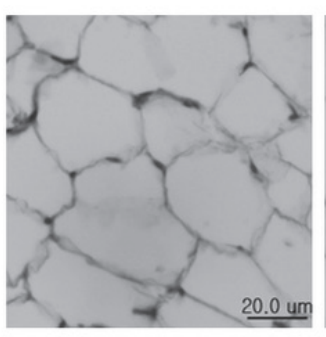

HFC

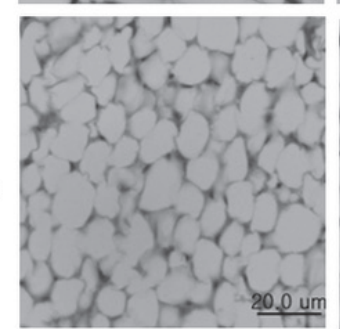

Retroperitoneal white adipose

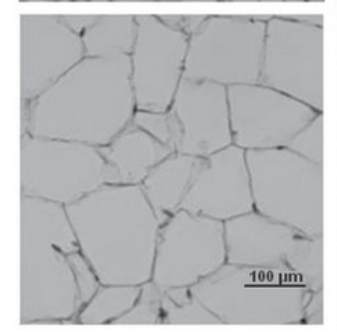

B

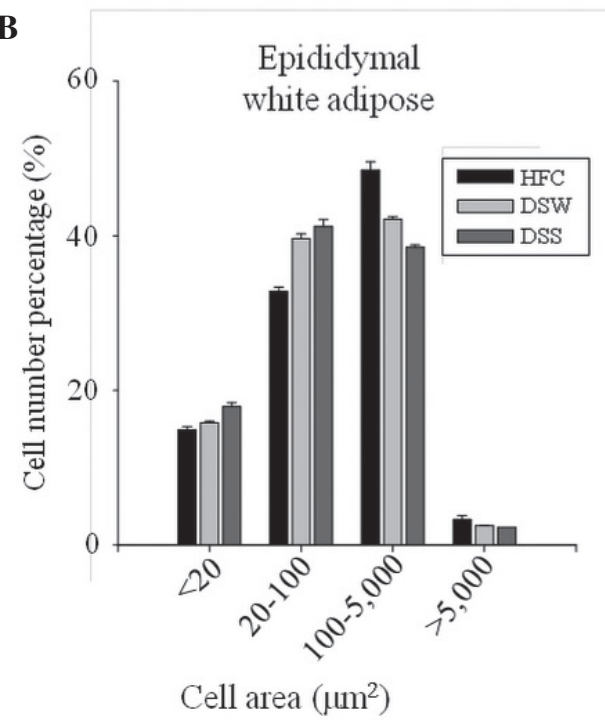

DSW
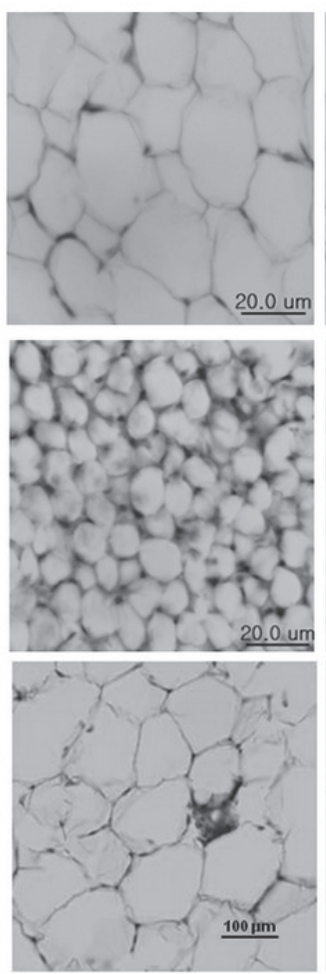

C
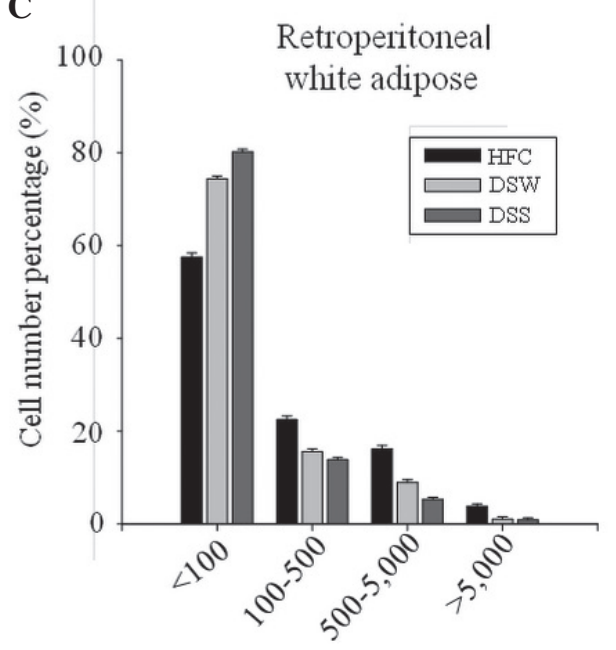

Cell area $\left(\mu \mathrm{m}^{2}\right)$

Figure 1. Effects of deep water and Sesamum indicum leaf extract on epididymal, retroperitoneal and brown adipose tissue morphology. (A) Histological sections (hematoxylin and eosin staining; magnification, $\mathrm{x} 400$ ). Mean adipocyte cell number percentage of (B) epididymal and (C) retroperitoneal white adipose tissue ( $\mathrm{n}=6)$. HFC, high fat control; DSW, deep sea water; DSS, DSW + $125 \mathrm{mg} / \mathrm{kg}$ Sesamum indicum leaf extract. 
Table IV. Effects of deep water and Sesamum indicum leaf extract on serum triglyceride and leptin levels.

\begin{tabular}{lcc}
\hline Group & Triglyceride $(\mathrm{mg} / \mathrm{dl})$ & Leptin $(\mathrm{ng} / \mathrm{ml})$ \\
\hline HFC & $467.1 \pm 88.4$ & $2.89 \pm 1.01$ \\
DSW & $140.3 \pm 13.0^{\mathrm{a}}$ & $0.85 \pm 0.11^{\mathrm{b}}$ \\
DSS & $121.7 \pm 14.3^{\mathrm{a}}$ & $0.72 \pm 0.10^{\mathrm{b}}$ \\
\hline
\end{tabular}

Values represent the mean \pm standard error of the mean $(n=6)$. Plasma parameters were analyzed in plasma samples obtained from the blood of 12 -h fasted mice. ${ }^{\text {a }} \mathrm{P}<0.01,{ }^{\mathrm{b}} \mathrm{P}<0.05$ vs. the HFC group. HFC, high-fat diet control; DSW, deep sea water; DSS, DSW + $125 \mathrm{mg} / \mathrm{kg}$ Sesamum indicum leaf extract.
A

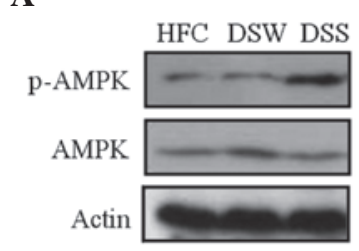

C

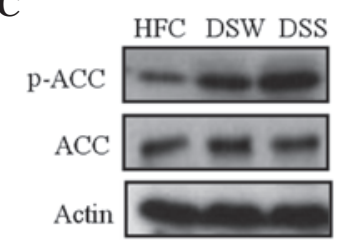

B

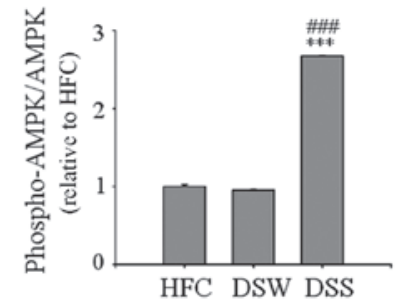

D

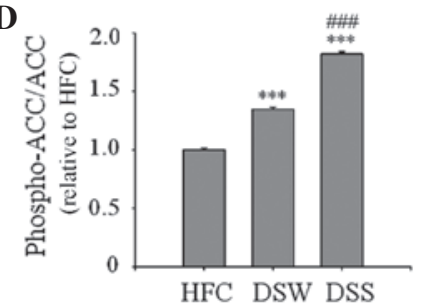

Figure 2. Western blot analysis of p-AMPK, AMPK, p-ACC and ACC levels in epididymal adipose tissue. (A) Representative western blots and (B) expression levels of p-AMPK and AMPK. (C) Representative western blots and (D) expression levels of p-ACC and ACC. ${ }^{* * *} \mathrm{P}<0.001$ vs. the HFC group; ${ }^{\# \# \#<0.001 ~ v s . ~ t h e ~ D S W ~ g r o u p . ~ p, ~ p h o s p h o ; ~ A M P K, ~ a d e n o s i n e ~}$ monophosphate-activated protein kinase; ACC, acetyl-CoA carboxylase HFC, high-fat diet control; DSW, deep sea water; DSS, DSW + $125 \mathrm{mg} / \mathrm{kg}$ Sesamum indicum leaf extract.

levels between the HFC group and the DSW and DSS groups. The insulin resistance index (HOMA-IR) values for the DSS-treated group were markedly decreased by $38.2 \%$ when compared with those in the HFC group (Table III). The plasma TG and leptin levels of the DSW- and DSS-treated groups were significantly lower than those in the HFC group (Table IV).

Histological observations. Histological analysis results showed that the sizes of the epididymal fat and retroperitoneal fat cells in adipose tissue from the DSW group were smaller than those from the HFC group, and that fat cell sizes in the DSS-treated group were smaller than those in the DSW-treated group. Similar results were also observed in scapular brown adipose tissues (Fig. 1).

Western blot analysis of AMPK and ACC activation. AMPK is a key regulator of intracellular fatty acid metabolism and plays a central role in the regulation of whole body energy

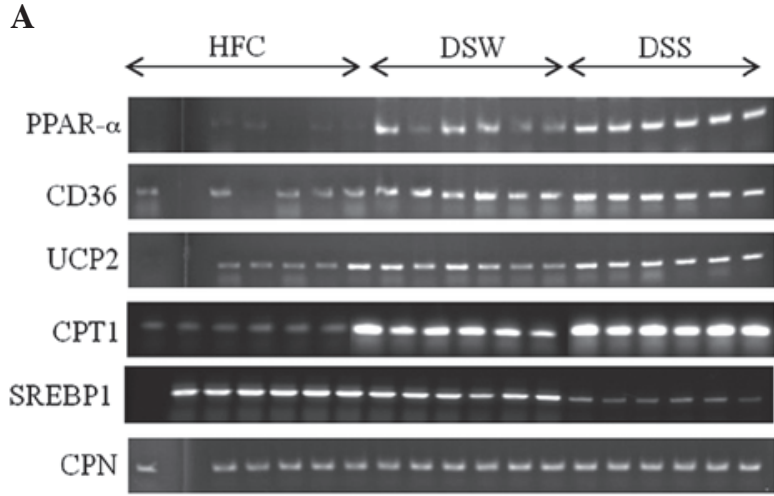

B

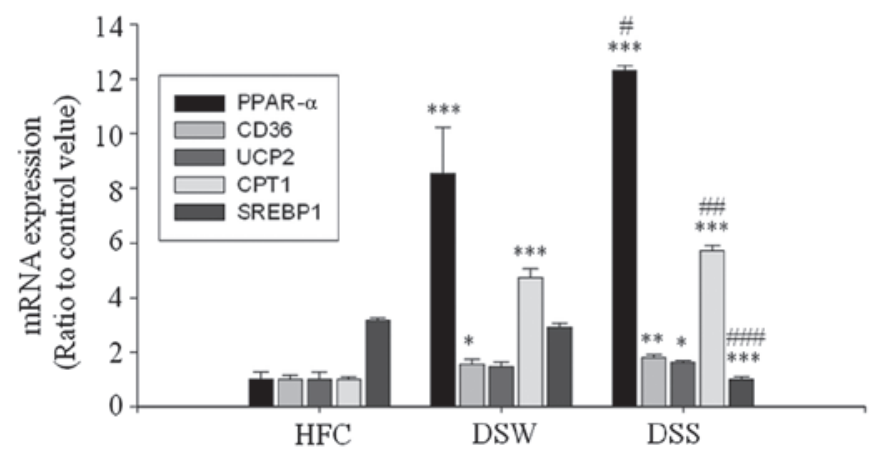

Figure 3. Reverse transcription-polymerase chain reaction analyses of PPAR- $\alpha$, CD36, UCP2, CPT1, SREBP1 and CPN mRNA expression in the epididymal adipose tissue of mice treated with deep sea water and Sesamum indicum leaf extract. (A) Electrophoretic results and (B) relative expression levels. ${ }^{*} \mathrm{P}<0.05,{ }^{* *} \mathrm{P}<0.01$ and ${ }^{* * *} \mathrm{P}<0.001$ vs. the HFC group; ${ }^{*} \mathrm{P}<0.05,{ }^{\# \#} \mathrm{P}<0.01$ and ${ }^{\# \# \#} \mathrm{P}<0.001$ vs. the DSW group. PPAR- $\alpha$, peroxisome proliferator-activated receptor- $\alpha$; CD36, cluster of differentiation 36; UCP, uncoupling protein 2; CPT1, carnitine palmitoyltransferase-1; SREBP1, sterol regulatory element-binding protein-1; HFC, high-fat diet control; DSW, deep sea water; DSS, DSW $+125 \mathrm{mg} / \mathrm{kg}$ Sesamum indicum leaf extract. CPN, cyclophilin.

homeostasis (19-21). In the present study, AMPK phosphorylation was measured by western blot analysis of the epididymal adipose tissue. As shown in Fig. 2, the levels of p-AMPK and p-ACC were significantly increased in the DSS group compared with those in the HFC and DSW groups, indicating the AMPL and ACC were activated (Fig. 2).

Expression of mRNA in epididymal adipose tissue. The results from the RT-PCR analysis of the total RNA obtained from the epididymal adipose tissue of the mice showed that DSS upregulated the expression of the lipolysis-associated mRNA PPAR- $\alpha$ and CD36, and energy expenditure-associated\# mRNA UCP2 and CPT1 (Fig. 3).

\section{Discussion}

Obesity is a major health problem in developed and developing countries $(5,22)$. Obesity develops when energy intake exceeds energy expenditure. HFD is a risk factor leading to whole-body fat accumulation and distribution, particularly the accumulation of visceral adipose tissue (23). Numerous studies have indicated that high levels of body fat are associated with an increased risk of the development of various diseases $(1,2)$. 
Anti-obesity foods and food ingredients may improve the physical condition, and also possibly prevent life-style-related diseases, if they are effective in reducing the accumulation of visceral fat (24). In the present study, whether DSS prevents HFD-induced obesity in ICR mice was examined. It was found that DSS significantly decreased body weight gain and adipose cell size in HFD-induced obesity, indicating that DSS may have anti-obesity activity. The reduction of body weight gain and adipose tissue size may be associated with an effect on adipocyte metabolism. In addition, plasma glucose levels, HOMA-IR values and plasma TG values were significantly lowered in mice treated with DSW and DSS, compared with those in the HFC group. This result suggests that DSW and DSS may have a beneficial effect in improving the insulin resistance induced by a HFD. Leptin is a major adipocyte-derived hormone that is involved in the regulation of food intake and energy expenditure. Therefore, the circulating leptin level correlates with the extent of obesity (25). According to the results of the present study, DSW and DSS significantly decreased plasma leptin levels in mice fed with a HFD. This result also indicates that DSS may have anti-obesity activity. Although weight gains between the HFC and DSW groups were not significantly different, fat mass and obesity-related parameters in DSW group showed a marginal difference compared with those in the HFC group. These results may be ascribed to the reduced level of leptin in the DSW group.

AMPK is a serine/threonine kinase that is activated when the intracellular AMP:ATP ratio increases. AMPK plays a key role in regulating carbohydrate and fat metabolism, serving as a metabolic master switch in response to alterations in cellular energy charge (26-28). AMPK is also an intercellular signal transmitting substance of leptin and adiponectin secretion from adipocytes $(29,30)$. ACC is a rate-limiting enzyme in the synthesis of malonyl-CoA, which is a critical precursor in the biosynthesis of fatty acids and a potent inhibitor of mitochondrial fatty acid oxidation. Inhibition of ACC by AMPK through phosphorylation leads to a fall in malonyl-CoA content and a subsequent reduction in fatty acid synthesis and increase in mitochondrial fatty acid oxidation via the allosteric regulation of CPT-1, which catalyzes the entry of long-chain fatty acyl-CoA into mitochondria (31). In the present study, DSW and DSS resulted in the significant phosphorylation of AMPK and ACC compared with that in the HFC group. These results may elucidate the mechanism by which DSW and DSS promote fatty acid oxidation, inhibit TG accumulation and enhance insulin sensitivity. The expression levels of target genes responsible for lipogenesis, lipolysis and energy expenditure were examined by RT-PCR. The results showed that DSW and DSS upregulated the mRNA expression of lipolysis-associated PPAR- $\alpha$ and CD36, and energy expenditure-associated UCP2 and CPT1 (Fig. 3). By contrast, DSW and DSS downregulated the mRNA expression of lipogenesis-related SREBP1.

In conclusion, this study demonstrated that DSW and DSS have preventive effects against HFD-induced obesity in ICR mice through enhancing the expression of lipolysis-associated PPAR- $\alpha$ and CD36 and energy expenditure-associated UCP2 and CPT1 at the mRNA level, and increasing fatty acid oxidation via AMPK activation in epididymal adipose tissue.
Therefore, these results suggest that this functional food may be beneficial for reducing body fat and/or preventing obesity.

\section{References}

1. Kopelman PG: Obesity as a medical problem. Nature 404: 635-643, 2000

2. Ahn J, Lee H, Kim S, Park J and Ha T: The anti-obesity effect of quercetin is mediated by the AMPK and MAPK signaling pathways. Biochem Biophys Res Commun 373: 545-549, 2008.

3. Hill JO and Peters JC: Environmental contributions to the obesity epidemic. Science 280: 1371-1374, 1998.

4. Beck B: Neuropeptides and obesity. Nutrition 16: 916-923, 2000.

5. Woods SC, Seeley RJ, Rushing PA, D'Alessio D and Tso P: A controlled high-fat diet induces an obese syndrome in rats. J Nutr 133: 1081-1087, 2003.

6. Woo MN, Bok SH, Lee MK, Kim HJ, Jeon SM, Do GM, Shin SK, Ha TY and Choi MS: Anti-obesity and hypolipidemic effects of a proprietary herb and fiber combination (S\&S PWH) in rats fed high-fat diets. J Med Food 11: 169-178, 2008.

7. Okamoto Y, Higashiyama H, Rong JX, McVey MJ, Kinoshita M, Asano S and Hansen MK: Comparison of mitochondrial and macrophage content between subcutaneous and visceral fat in db/db mice. Exp Mol Pathol 83: 73-83, 2007.

8. Shono M, Shimizu I, Aoyagi E, Taniguchi T, Takenaka H, Ishikawa M, Urata M, Sannomiya K, Tamaki K, Harada N, et al: Reducing effect of feeding powdered nacre of Pinctada maxima on the visceral fat of rats. Biosci Biotechnol Biochem 72: 2761-2763, 2008.

9. Hainer V, Toplak H and Mitrakou A: Treatment modalities of obesity: What fits whom? Diabetes Care 31: 269-277, 2008.

10. Derosa G, Cicero AF, Murdolo G, Piccinni MN, Fogari E, Bertone G, Ciccarelli L and Fogari R: Efficacy and safety comparative evaluation of orlistat and sibutramine treatment in hypertensive obese patients. Diabetes Obes Metab 7: 47-55, 2005.

11. Hwang HS, Kim SH, Yoo YG, Chu YS, Shon YH, Nam KS and Yun JW: Inhibitory effect of deep-sea water on differentiation of 3T3-L1 adipocytes. Mar Biotechnol 11: 161-168, 2009.

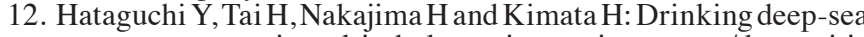
water restores mineral imbalance in atopic eczema/dermatitis syndrome. Eur J Clin Nutr 59: 1093-1096, 2005.

13. Katsuda S, Yasukawa T, Nakagawa K, Miyake M, Yamasaki M, Katahira K, Mohri M, Shimizu T and Hazama A: Deep-sea water improves cardiovascular hemodynamics in Kurosawa and Kusanagi-Hypercholesterolemic (KHC) rabbits. Biol Pharm Bull 31: 38-44, 2008.

14. Hwang HS, Kim HA, Lee SH and Yun JW: Anti-obesity and antidiabetic effects of deep sea water on ob/ob mice. Mar Biotechnol (NY) 11: 531-539, 2009.

15. Ha BG, Park JE, Shin EJ and Shon YH: Effects of balanced deep sea water on adipocyte hypertrophy and liver steatosis in high-fat diet induced obese mice. Obesity (Silver Spring) 22: 1669-1678, 2014.

16. Hahm TS, Park SJ and Martin Lo Y: Effects of germination on chemical composition and functional properties of sesame (Sesamum indicum L.) seeds. Bioresour Technol 100: 1643-1647, 2009.

17. Lee J, Kausar T and Kwon JH: Characteristic hydrocarbons and 2-alkylcyclobutanones for detecting gamma-irradiated sesame seeds after steaming, roasting and oil extraction. J Agric Food Chem 56: 10391-10395, 2008.

18. Institute of Laboratory Animal Research, Commission on Life Sciences and National Research Council: Guide For The Care And Use Of Laboratory Animals. National Academy Press Washington, DC, pp1-136, 1996.

19. Yin HQ, Kim M, Kim JH, Kong G, Kang KS, Kim HL, Yoon BI, Lee MO and Lee BH: Differential gene expression and lipid metabolism in fatty liver induced by acute ethanol treatment in mice. Toxicol Appl Pharmacol 223: 225-233, 2007.

20. Horton JD, Goldstein JL and Brown MS: SREBPs: Activators of the complete program of cholesterol and fatty acid synthesis in the liver. J Clin Invest 109: 1125-1131, 2002.

21. Hardie DG: The AMP-activated protein kinase pathway - new players upstream and downstream. J Cell Sci 117: 5479-5487, 2004.

22. Jeon JR and Kim JY: Effects of pine needle extract on differentiation of 3T3-L1 preadipocyte. Biol Pharm Bull 29: 2111-2115, 2006. 
23. Jun HS, Hwang K, Kim Y and Park T: High-fat diet alters PP2A, TC10 and CIP4 expression in visceral adipose tissue of rats. Obesity (Silver Spring) 16: 1226-1231, 2008

24. Saito M, Ueno M, Ogino S, Kubo K, Nagata J and Takeuchi M: High dose of Garcinia cambogia is effective in suppressing fat accumulation in developing male Zucker obese rats, but highly toxic to the testis. Food Chem Toxicol 43: 411-419, 2005.

25. Ogawa Y, Masuzaki H, Ebihara K, Shintani M, Aizawa-Abe M, Miyanaga F and Nakao K: Pathophysiogical role of leptin in lifestyle-related diseases: Studies with transgenic skinny mice overexpressing leptin. J Diabetes Complications 16: 119-122, 2002.

26. Hardie DG and Carling D: The AMPK-activated protein kinase-fue gauge of mammalian cells. Eur J Biochem 246: 259-273, 1998.

27. Hardie DG, Carling D and Carlson M: The AMP-activated/SNF1 protein kinase subfamily: Metabolic sensors of the eukaryotic cell? Ann Rev Biochem 67: 821-855, 1998.
28. Hardie DG, Scott JW, Pan DA and Hudson ER: Management of cellular energy by energy by the AMP-activated protein kinase system. FEBS Lett 546: 113-120, 2003

29. Yano W, Kubota N, Itoh S, Kubota T, Awazawa M, Moroi M, Sugi K, Takamoto I, Ogata H, Tokuyama K, et al: Molecular mechanism of moderate insulin resistance in adiponectin-knockout mice. Endocr J 55: 515-522, 2008.

30. Janovská A, Hatzinikolas G, Staikopoulos V, McInerney J, Mano $\mathrm{M}$ and Wittert GA: AMPK and ACC phosphorylation: Effect of leptin, muscle fibre type and obesity. Mol Cell Endocrinol 284: 1-10, 2008

31. Velasco G, Geelen MJ and Guzmán M: Control of hepatic fatty acid oxidation by 5'-AMP-activated protein kinase involves a malonyl-CoA-dependent and a malonyl-CoA-independent mechanism. Arch Biochem Biophys 337: 169-175, 1997. 